\title{
OBtiginal Communitations.
}

\section{CONTRIBUTIONS TO CLINICAL SURGERY.}

By Oliver Penberton, Esq., Surgeon to the Birmingham General Hospital.

\section{IV.-Fissured Fracture of the Cranium.}

Probably no part of the body is liable to so great a variety of accidents as the cranium; but, various as are the injuries which it receives, both in civil and military life, their diversity is scarcely to be compared with the unceasing difference in their mode of infliction. The careful recognition of the his. tory of every particular relating to grave injuries of the skull, may, in some instances, justify the surgeon in adopting a mode of treatment which, under other circumstances, would not be suggested; whilst at other times the minutest observation as to the mode in which the accident occurred, fails to guide him to a correct knowledge of the real state of the disordered parts. The succeeding case and observations will illustrate the correctness of these remarks.

CAsE. L. L., aged 47, a well-sinker, was brought to the Birmingham General Hospital; on the morming of August 6th, 1854 , having met with the following accident. Whilst working down the shaft of a well some yards in depth, the bucket, shod with iron, which his assistant was raising by the windlass, suddenly fell, and unhappily alighted on his bead. The blow having rendered him insensible, he was carried as soon as possible to the hospital.

On examining him half an hour afterwards, I found the following conditions present. There was an incised wound of the scalp, about four inches long, situated over the right parietal bone, and extending also across the inter-parietal suture to the left; the direction of the wound was horizontal, with the extremities curving forwards, so that the concavity looked towards the front of the cranium. Its superior angle was distant about two inches from the apex of the occipitoparietal suture. On passing the finger into the wound, a fis. sured fracture of the skull was detected nearly three inches long, having a direction corresponding to the external injury. Small fragments of bone were picked out of the fissure by the fingers, and the parts being otherwise cleared, the dura mater was found to be exposed, but apparently undivided. There was not the least evidence of depression of the margins of the bone along which the fissure travelled, either within or without the cranium. The patient was unconscious, pale, and somewhat cold. His pulse was quick, but the breathing natural, and the pupils rather contracted. I directed that the wound should be covered with lint wetted in cold water ; that warmth should be applied to the surface of the body; that a purge of calomel and jalap should be given towards evening, and a stimulating enema four hours afterwards.

He continued in a state of profound insensibility for six days after the accident, and then recognised his wife, who had been watching by his bed-side since his admission into the hospital. During this period, his symptoms never varied. The breathing was not laborious, nor were the pupils otherwise than slightly contracted. His pulse became, however, somewhat quicker and more feeble, as time went on. He swallowed with difficulty, his only nourishment consisting of a spoonful of milk and broth, administered with care and frequency. The bowels were relieved by enemata, and the gums were slightly touched by calomel.

His amendment, after this, though slow, was sufficiently satisfactory. The wound suppurated healthily, and some small portions of bone were picked out from time to time. His mental recovery appeared also favourable; and his answers to questions regarding the occurrence, showed that his memory was not impaired.

He was discharged from the hospital six weeks after his admission. The wound had then healed, with the exception of a small sinus.

I saw no more of him until January 1855 , about five months after the accident, when I encountered him by chance in the street, and was struck at once by his altered appearance. 382
He looked weak in body and mind, and replied anything but clearly to my questions. His wife informed me that he had not resumed his work since the occurrence, and that of late he had become restless and irritable to all about him.

He was re-admitted, and at once placed under a course of mercury. During the few weeks he remained in, he greatly improved; and left of his own accord, before I considered it safe for him to do so. The wound shewed a deep sulcus, and had discharged one or two small pieces of bone, but the sinus had entirely closed.

My further knowledge of this poor fellow happened under circumstances somewhat singular. One day, in the month of March, in the last year, Mr. T. H. Bartleet, a highly intelligent student of the General Hospital, requested my attention to a portion of fractured skull which he had recently obtained from a post mortem examination of a patient who had died in epileptic convulsions. On examining the specimen, I was at once struck with the peculiar shape of the fissure-rounded, as if done by the iron edge of a bucket; and, on a little inquiry, was soon satisfied of its having belonged to the patient whose injury I have above detailed.

From the patient's wife, and from Dr. Jordan, of this town, I was enabled to gather the following history of his state subsequent to the time of his second discharge from the hospital. Eleven months after the accident, it seems he was so fairly recovered, that he was enabled to resume his employment, and remained at work for a year without hindrance. He was then laid up for a month-being "out of sorts", as the wife expressed it. Afterwards, he again resumed work. In the latter part of 1857, he became irritable; wandered about in odd kinds of places; and at times did not know what he was doing. In the November, he was seized with a fit for the first time.

Dr. Jordan informs me, that when he first knew him, in the early part of December 1857 , he was imbecile, or nearly so. He was summoned to visit him one night, and found him in a distinct epileptic fit. The pupils were equal; the pulse feeble. There was foaming at the mouth, and much convulsive movement of the extremities, and the features were much distorted; but no paralysis existed, nor was one side more convulsed than another. Fit succeeded fit, and he remained in this state about four days, being quite comatose in the intervals between the convulsions. He was blistered at the neck and the soles of the feet, a turpentine enema was given, and ammonia ad. ministered internally. He recovered, and returned to his now ordinary condition of imbecility. He walked about, and there was no dragging movement of the limbs; but much headache. He was unable to work; and suffered much from headache.

March 10th, 1858. He went out, grew bewildered, and lost his way, and, in returning home, strayed into a neighbour's house, where he soon fell down in a fit. As on the previous occasions, fits succeeded each other, and he died five hours after the first attack.

Dissectron thirty hours after death. The head alone was examined. The dura mater was thinned, and adherent round the seat of fracture. The brain was rather softened at the same spot. The ventricles contained a good deal of fluid. The portion of skull involved in the fracture was removed. I will now proceed to describe the appearances presented by this. It comprises an elliptical piece of the vault of the skull, including in its dimensions about equal parts of either parietal, and that part of the occipital where it joins the sagittal suture. From point to point it measures in length seven inches and a half, and in breadth rather more than three. Viewed externally (Fig. 1), the fissure is seen to start from a point in the sagittal suture distant two inches from the commencement of the lambdoid, thence it passes outwardly and curving forwards terminates at a distance of two inches and a half from its commencement. The fissure is not complete throughout, being bridged across by a junction, probably of new ossific material. A probe, passed on either side of this bridge, rests on a ledge of bone, formed by the projection internally of a mass of thickened bony structure; from this there is a ragged aperture opening directly into the cranial cavity. The margins of the fissure are rounded off, and the adjacent surfaces of the external table are without elevation or depression of any kind. Viewed internally (Fig. 2), a mass of bone is seen projecting abruptly in a direction from the external fissure, corresponding to its anterior aspect. This measures two inches in length by three quarters of an inch in breadth, and it extends inwards from the ordinary level of the internal table adjacent half an inch. Its free surface presents the usual appearance of the internal table, or tabula vitrea, of the skull-the furrows of the meningeal vessels being yet distinct as they run across it. 
Anteriorly, it is bevelled off in a gradual thickening of the bone, and in the presence of numerous irregular elevations and depressions of its structure, similar to the excavations

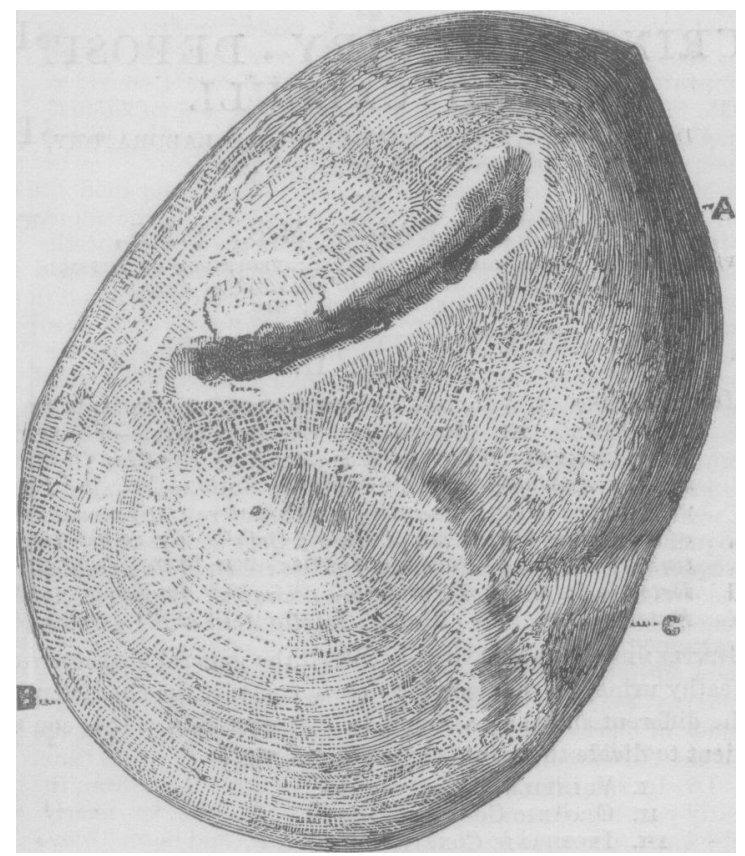

Fig. 1.-The external view of the fracture-its concavity looking anteriorly. (Reduced one-third the natural size.)

A. Portion of right parietal bone.

13. Portion of left parietal bone.
C. Portion of occipital bone.

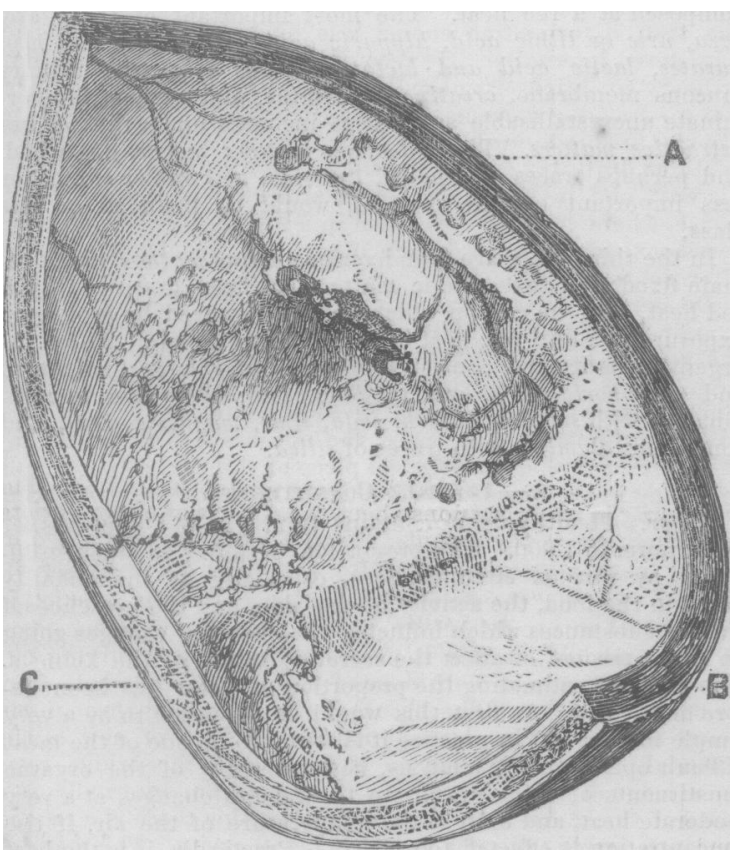

Fig. 2.-Interior view of the fracture.

A. The right parietal bone, shewing the depressed inner table.

1. The left parietul bone.

C. The occipital, and the groove for the longitudinal sinus.

observed in some skulls for the so called "glands of Pacchioni". Posteriorly, it presents a rough thickened margin; beneath which, a ragged opening, three quarters of an inch in length, communicates with the outer fissure. A smaller opening, to the outside of this, also opens into the same fissure. The remaining internal surface of the cranium about the seat of injury presents several elevations of the inner table as well as in the neighbourhood of the longitudinal sinus. The walls of the skull are greatly thickened; that nearest to the depressed bone measuring seven lines in breadth; whilst the same aspect presents no appenrance whatever of an interral between the tables, it being exceedingly dense, hard, and compact.

REMARKs. In reflecting on the history of this patient's condition from the first, especially as to the nature of the injuries received, I have arrived at the following conclusions:-

1. That he suffered from concussion of the brain.

2. That the skull had undergone a fissured fracture of its axternal table.

3. That the internal table, also, was fractured, and driven in on the dura mater.

The presence of this latter complication was unmarked by the advent of symptoms indicating compression of the brain. During the entire period comprised in the two occasions of his being under my immediate notice, a period of six months, he never had any symptoms which betokened compression of the brain. Irritation of the brain was unquestionably present on his being admitted into the hospital on the second occasion, and, indeed, evidences of some slow inflammatory action in the coverings of that organ, of a marked character, which yielded to the mercurial treatment that was adopted; but, with all this, the symptoms never pointed to the presence of depressed bone, and were fairly explained, in my mind, at the time, by the injury which the dura mater had most probably received from its exposure, as well as from its contiguity to the seat of fracture.

That these symptoms had their origin from an insidious form of inflammatory action, and not from the effects of de. pressed bone, is, I think, borne out by the restoration to health, which followed his discharge from the hospital-a restoration so complete, that he pursued his employment for twelve months without hindrance.

Three years and four months after the receipt of his injury, this man, having manifested symptoms of irritability, and becoming otherwise strange and unlike bimself, is seized with an epileptic fit. He becomes comatose, and the fits are frequent. Yet there is no paralysis, and, what is remarkable, no indica. tion of one side of the brain being the seat of irritation more than another.

Three months after the first epileptic attack, the man dies; and previously he is an imbecile in mind as well as body.

Now, had my friend Dr. Jordan been in possession of the earlier facts relating to this man's injury, as I was, I cannot but think that he would have been led to a consideration of the possibility of relief being obtained for him by surgical interference; but this was not so, and he had only the merest outline of a former history conveyed to him, whereby he could form an opinion as to the probable connexion of the wound, which he could still trace on the skull with the formidable symptoms that were then present. The dissection, however, of the parts after death supplied the deficiences that were wanting to make this connexion apparent. Had this patient fallen under my notice in his later days, I should have felt justified in proposing to his friends that an exploration, by. means of the trephine, should be made of the internal margins of the fissure; and I should not have hesitated to have removed the ingrowing table at this stage of his complaint, any more than I should at an earlier one, had symptoms been present to have indicated the propriety of such treatment.

By symptoms I mean the mechanical evidences of depressed bones, not the cerebral and constitutional symptoms of the accident. The advent of these should be anticipated by the removal of that which sooner or later will lead to their production.

Where symptoms manifest themselves, either in the shape of convulsions, continued headache, or in epileptic seizures, subsequent to a former injury of the head, their connexion with the injury is so obvious that surgeons have not hesitated to resort to the trephine. That such treatment may be attended with success, the cases of the elder Cline (System of Surgery, J. M. Chelius, Transl. South, vol.i, p. 418) and others testify.

The experience of Mr. Guthrie (Injuries of the Head affecting the Brain, page 86) relative to the character of fractures of the cranium, when inflicted by cutting instruments falling perpendicularly, bears strongly on the nature of this case, and points to the methods of treatment and examination that should be adopted. When the inner table has been penetrated, the case assumes, in his judgment, a most serious aspect, inasmuch as "almost always" this table will be found 
broken to a far greater extent than the outer; this latter surface merely presenting the separation of the edges of the fissure.

Arguing on the frequency of this occurrence in such injuries, he recommends that the most careful examination should be made with the probe, in order that any depression of the internal table may, if possible, be at once ascertained. If present, notwithstanding the absence of symptoms of compression, the trephine is to be applied, and the portions of bone removed, in order to guard against their occurrence hereafter. He thus sums up his convictions on this matter:"A patient very often survives a mere depression of the skull; he may, and occasionally does, survive a greater depression of the inner than of the outer table; but I do not believe that he ever does survive and remain in tolerable health after a depression with fracture of the inner table, when portions of it have been driven into the dura mater." (Injuries of the Head affecting the Brain, p. 94.)

I cannot but think that, had the symptoms led me to have raised the inner table of this patient's skull when I first examined him, he would, in all probability, have had a better chance of permanent recovery.

That a fracture of the internal table, accompanied by depression, occurred at the outset, I have already stated to be my conviction; and I think that any one who examined the specimen, or who now attentively inspects the woodcuts which illustrate these observations, will arrive at the same conclusion. The pressure on the brain exercised by this could not have been at first to any extent beyond a most moderate amount. After a time, as inflammatory action arose in the bones around the injury, my opinion is that a filling in of the diploe by new bone took place, which, as it grew, had the effect of compelling inwards the broken portion of the inner table more and more, until at length that time arrived when its influence on the brain could no longer be endured.

I would remark, also, that the congestion of the vessels of the head, repeatedly present, would appear to have led to that general thickening of the bones of the cranium which was observable in this case, and which brought portions of them to a breadth almost comparable with the thickness of a skullcap said to be in the possession of Mr. Quekett, nearly an inch in thicliness, and originating in a blow received some years before death, from the effects of which recovery had apparently taken place. (Holden's Human Osteology, 2nd edit., p. 110.)

We may fairly, then, derive some practical conclusions from the foregoing case. They are briefly stated thus :-

1. The necessity of making a most minute examination of all cases of fissured fracture of the cranium, especially where the injury has been intlicted by cutting instruments falling perpendicularly, although there are neither mechanical nor other evidences present of depression of the inner table of the skull.

2. Supposing the inner table is found to be driven inwards on the dura mater; and, although no symptoms of compressed brain are present, the surgeon, in my judgment, will give his patient a better chance of avoiding future mischief by at once raising, and, if necessary, removing, that which sooner or later must destroy life.

3. There are sometimes cases of epileptic seizures and im becility, or of continued headache, occurring at a remote period from a former injury to the head, which call for the use of the trephine.

Drinking Fountains for Westminster. At a meeting of the vestry of St. James's, Westminster, held on Friday, May 6th, the Rev. J. C. Kemp, in the chair, a communication was received from Samuel Gurney, Esq., in which the advantages of public drinking fountains were stated, and the cooperation of the vestry with the association for promoting their erection was invited. The Hon. F. Byng moved a resolution to the effect, that the vestry propose to the Free Drinking Fountain Association to pay for the supply of water to the fountains erected by the association. Mr. Beale seconded the resolution, and Dr. Lankester, the medical ofticer of health, urged the necessity of such public drinking fountains being established, and hoped they would be made ornamental as well as useful. Mr. Bidgood supported the resolution, which was unanimously agreed to.

Acade uy of Sciences in Paris. On April 29th, Professor Owen was elected a foreign associate of this learned body, in the room of the late celebrated botanist Robert Brown.

\section{A countse of afentures}

\section{URINE, URINARY DEPOSITS, AND CALCULI.}

DELIVERED AT THE Pathological labolatory, DURING THE SESSION 1857.58.

BY

LIONEL BEALE, M.B., F.R.S.,

PHYSICIAN TO KING'S COLLEGE hOSPITAL; PROFESSOR OF PHYSIOLOGY AND GENERAL AND MORBID ANATOMY IN KING'S COLLEGE, LONDON; ETC.

\section{Lecture II.}

Healthy Urine. I. Volatile Constituents. Ir. Organic ConStITUENTs. III. InORGanic Constituents. - Volatil. Constituents: Water; Carbonic Acid; Peculiar Organic Acids : Ammonia and Ammoniacal Salts.-ORganrc CoNstituents: Urea; Quantity ; Characters ; Circumstances affecting the Formation of Urea; Origin : Creatine : Crea tinine: Guanine : Sarcine: Inosite : Uric Acid; Quantity Detection; Mode of Formation : Urates : Hippuric Acid: Extractive Matters : MIucus : Lactic Acid and Lactates.

Gentremen,-After having discussed the general characters of heathy urine, we may now pass on to consider the characters of the different substances found in this excretion. It is convenient to divide them into three classes, viz.:

I. Voratile Constituents;

ir. Organic Constituents;

iIr. Inorganic Constituents.

The first class includes those substances which are volatilised at the temperature of a steam-bath ( $212^{\circ}$ or less). The most important of these are, water, carbonic acid, and certain ammoniacal salts.

The second class contains those organic constituents which are not volatilised at a temperature of $212^{\circ}$, but which are decomposed at a red heat. 'The most important of these are, urea, uric or lithic acid, hippuric acid, with urates and hip purates, lactic acid and lactates, mucus from the urinary mucous membrane, creatine, creatinine, and various indeterminate uncrystallisable substances included under the head of extractive $n$ atters. The colouring matters before described, and perhaps traces of leucine, tyrosine, and one or two other less important organic matters, would be included in this class.

In the third class are found various saline matters which remain fixed after the organic matter has been destroyed by a red heat, and the carbon which results removed by prolonged exposure to a dull red heat in contact with the air. These inorganic constituents consist principally of chlorine, sulphuric and phosphoric acids, and, in some cases, nitric acid, in combination with sodium, potash, soda, lime, magnesia, iron, and sometimes alumina, with traces of silica.

\section{I.-Volatir.e Constituents.}

Water. Healthy urine contains from 940 to 960 grains, or even more, in 1,000. The proportion of water is much influenced by various circumstances, especially by the quantity taken in the food, the activity of the skin, and the presence of various substances which influence the chemical changes going on in the tissues, or affect the secreting action of the kidneys. The mode of estimating the proportion of water has been before alluded to. At first this would be supposed to be a very simple matter, but in practice it is found to be one of the most difficult operations in analysis, because many of the organic constituents of urine are prone to undergo changes at a very moderate heat, and even at the temperature of the air, if the concentration is effected too slowly. Practically, it is the best plan to concentrate the urine at a temperature of $100^{\circ}$, and then continue the evaporation in vacuo over sulphuric acid until the residue ceases to lose weight.

Carbonic Acid is held in solution in fresh urine: indeed, traces may be detected in all the animal fluids. Its presence may be shown by passing some pure hydrogen gas through urine. After the gas has traversed the urine, it should be conducted into pure lime water, which will become turbid if there be an appreciable quantity of carbonic acid present. This experiment is founded upon the fact that, if one gas be passed 